UCRL-JC-121231

PREPRINT

CONF $-95 / 155-53$

Discrete-Fracture Modeling of Thermal-Hydrological Processes at Yucca Mountain and the LLNL G-Tunnel Heater Test

John J. Nitao

Thomas A. Buscheck

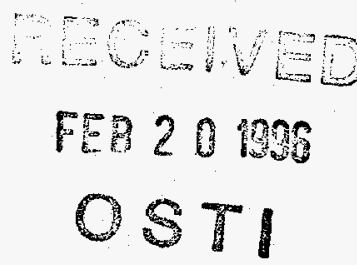

This paper was prepared for submittal to the

Materials Research Society

Boston, $M A$

November 27 - December 1, 1995

November 9, 1995

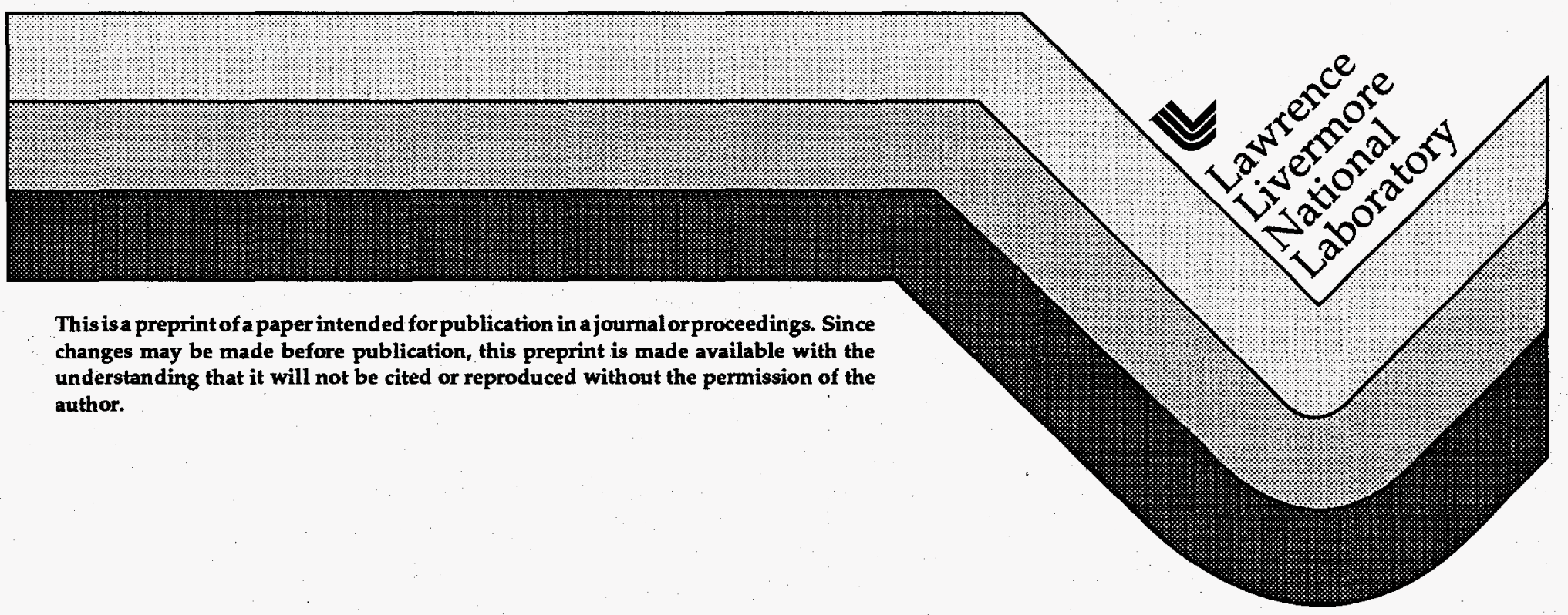




\section{DISCLAIMER}

This document was prepared as an account of work sponsored by an agency of the United States Government. Neither the United States Government nor the University of California nor any of their employees, makes any warranty, express or implied, or assumes any legal liability or responsibility for the accuracy, completeness, or usefulness of any information, apparatus, product, or process disclosed, or represents that its use would not infringe privately owned rights. Reference herein to any specific commercial products, process, or service by trade name, trademark, manufacturer, or otherwise, does not necessarily constitute or imply its endorsement, recommendation, or favoring by the United States Government or the University of California. The views and opinions of authors expressed herein do not necessarily state or reflect those of the United States Government or the University of Califomia, and shall not be used for advertising or product endorsement purposes. 


\section{DISCLAMMER}

Portions of this document may be illegible in electronic image products. Images are produced from the best available original document. 


\title{
DISCRETE-FRACTURE MODELING OF THERMAL-HYDROLOGICAL PROCESSES AT YUCCA MOUNTAIN AND THE LLNL G-TUNNEL HEATER TEST
}

\author{
JOHN J. NITAO and THOMAS A. BUSCHECK
}

Lawrence Livermore National Laboratory, P.O. Box 808, Livermore, CA 94550

\section{ABSTRACT}

An in situ heater test was performed at G-Tunnel, Nevada Nuclear Test Site, to investigate the thermal-hydrological response of unsaturated, fractured volcanic tuff under conditions similar to those at Yucca Mountain. The NUFT flow and transport code was used to model the test using discrete-fracture and equivalent-continuum approaches. Nonequilibrium fracture flow and thermal buoyant gas-phase convection were found to be the likely causes for observed lack of condensate imbibition into the matrix. The potential repository at Yucca Mountain was also modeled. Disequilibrium fracture flow is predicted to occur for less than a hundred years after emplacement followed by a period of fracturematrix equilibrium, during which the equivalent-continuum and discrete-fracture models give almost identical results.

\section{INTRODUCTION}

The U.S. Department of Energy is investigating the suitability of Yucca Mountain, Nevada, as a potential site for storage of high-level nuclear waste. Numerical models of thermal-hydrological processes show that decay heat can either significantly improve or degrade repository performance by affecting waste-package (WP) temperature and humidity environment [1]. Decay heat can also move substantial amounts of water vapor across various length scales [2] and can influence the infiltration flux pattern passing through the repository. Infiltration of meteoric water or drainage of condensate can give rise to water dripping onto WPs, resulting in accelerated corrosion rates and advective and diffusive transport pathways for radionuclides. Effective repository design must take into account both potentially negative and positive impacts of thermal design decisions. The technical basis for such decisions must be derived from an understanding of physical and chemical processes obtained through numerical models and laboratory and field experiments.

Thermally driven moisture movement in the unsaturated zone at Yucca Mountain has been modeled in the past using either equivalent-continuum (ECM) or (less commonly) discrete-fracture (DFM) models. The ECM assumes local thermodynamic equilibrium between the fractures and matrix within a composite representative elementary volume (for a description of an implementation of the ECM see Nitao [3]). It is, therefore, a singlecontinuum model with composite characteristic curves given as functions of bulk-averaged saturation. The DFM, on the other hand, separates the fractures and matrix into distinct spatially discretized domains, which, therefore, can represent disequilibrium between matrix and fractures. Because of this feature, the DFM is well suited to investigating the dynamics of decay-heat-generated condensate, on how much water imbibes into the matrix by matric suction or drains down fractures. However, the ECM is much more computationally efficient than the DFM, so that it is important to understand conditions under which use of the ECM is appropriate.

Comparisons of thermal-hydrological behavior between the ECM and the DFM by Pruess et al. [4] assumed axisymmetry with no gravity, and there was, therefore, very little difference between the results obtained by the two approaches. Our work shows that the influence of gravity can lead, in some cases, to significant differences. Forsythe [5] has performed one of the few thermal-hydrological calculations with discrete fracture and matrix elements including the effect of gravity. However, our experience and theoretical work suggests that Forsythe's matrix grid resolution was not fine enough to accurately 
calculate the matrix-fracture imbibition term, which strongly affects whether condensate drains.

\section{PROCESSES DRIVING MOISTURE MOVEMENT}

About 6 to $9 \%$ of the volume of the matrix rock at the repository horizon is occupied by liquid water. Decay heat can vaporize significant amounts of this pore water under both subboiling and boiling conditions. Which mechanisms dominate transport of the resulting vapor depends on the overall connectedness and fluid conductivity of the fracture system, as characterized by the large-scale bulk permeability $k_{b}$ [2]. There are three regimes with respect to advective gas transport, which are characterized by $k_{b}$ ranges: (1) low- $k_{b}$ range $\left(k_{b}<1-10\right.$ millidarcy), (2) intermediate- $k_{b}$ range (1-10 millidarcy $<k_{b}<1-10$ darcy), and (3) high- $k_{b}$ range ( $k_{\mathrm{b}} \geq 1-10$ darcy). In the intermediate- and high- $k_{\mathrm{b}}$ ranges, advective gas transport is not throttled by $k_{b}$ and can therefore dominate moisture movement at the drift and repository scales. Gas-phase pressure gradients generated by the evolving water vapor drive gas (air and water vapor) away from the dehydrating (boiling) region; this advection is the primary mode of vapor transport for the intermediate- $k_{\mathfrak{b}}$ range, while it is one of the two primary modes for the high- $k_{\mathfrak{b}}$ range. In the high- $k_{\mathfrak{b}}$ range, the other primary mode of vapor transport is decay-heat-driven buoyant gas-phase convection. For the low- $k_{\mathrm{b}}$ range, because advective vapor transport is throttled by $k_{b}$, vapor diffusion is the primary mode of vapor transport; vaporization creates a region of increased vapor pressure (centered at WPs), which causes an outward diffusive vapor flux.

As water vapor in fractures is driven away from the repository, it reaches regions in which the temperature is below the local boiling point of water, where it condenses. Some of the condensate will be imbibed into the matrix by suction potentials. The remaining condensate will drain downwards in fractures by gravity, imbibing into the matrix as it travels, until either (1) it returns to the dehydrating region, where it is revaporized, (2) all of the water in the fracture is eventually imbibed into the matrix, (3) the fracture dead-ends, or (4) the water table or perched water body is reached. Water in (1) may recondense again above the dehydrating zone, where it can repeat the process, creating a refluxing system [3] called a gravity-driven heat pipe.

\section{THE NUFT NUMERICAL MODEL}

The NUFT (Nonisothermal Unsaturated-Saturated Flow and Transport) computer code was used to perform the simulations. NUFT is a highly efficient and robust integrated finite difference code that describes the flow of multiple phases and transport of multiple components in porous media under isothermal or nonisothermal conditions [6]. It solves the (nonlinear) partial differential equations for the balance of component mass and energy. NUFT has an extensive suite of linear equation solvers that allows efficient solution of practical three-dimensional problems that have tens of thousands of elements, great contrasts in element size, and sharp nonlinearities in the governing equations. For this work NUFT was configured to solve the flow and transport of air, water, and energy. Flow of fluid phases is governed by the multiphase version of Darcy's law, the diffusion of air and water vapor by Fick's law, and thermal conduction by Fourier's law. Air, water vapor, and heat are transported by fluid advection in two phases, aqueous and gaseous. Local thermodynamic equilibrium is assumed between solid and fluid phases. Water property values are calculated from steam tables. The code calculates the vaporization and condensation of water, and the resulting absorption or release of latent heat, based on local thermodynamic equilibrium.

MODELING THE G-TUNNEL HEATER TEST 
A field test [7] (Prototype Engineered Barrier Test) was performed in 1988-1989 by Lawrence Livermore National Laboratory for the Yucca Mountain Project in the G-tunnel Complex at the Nevada Nuclear Test Site. The test took place within the Grouse Canyon member of the formation, a fractured welded tuff similar to that at the potential Yucca Mountain repository horizon. A 3-kW, 3-m-long heater assembly was emplaced into a horizontal borehole $30 \mathrm{~cm}$ in diameter and was energized for approximately 130 days followed by a 65 day linear rampdown period. Thermocouples, neutron probes, and psychrometers monitored the thermal and moisture response. Packed air-injection tests were performed before and after heating, indicating bulk permeabilities mostly within the 1-100 darcy range. Some important observations were the following: (1) temperatures generally followed a thermal conduction profile, except in a region to the side of the heater where, for a time, temperatures stayed at the boiling point; (2) the drying volume was accurately predicted by the ECM; (3) local drying in the matrix occured mostly adjacent to fractures; (4) gas phase pressures in the matrix were higher than in fractures; (5) slightly more drying was observed below the heater than above; (6) temperature profiles at some points were slightly higher above the heater than at corresponding distances below; (7) there was very little imbibition of condensate; and (8) some drainage into the borehole from fractures occurred early in the test.

The test was simulated using NUFT to construct a three dimensional hybrid DFM/ECM system. A single discrete fracture is represented by a two-dimensional plane of elements that traverses the heater at its midplane. The matrix on both sides of the fracture is $0.15 \mathrm{~m}$ thick and is modeled by a three-dimensional slab of elements. The rest of the model consists of a three-dimensional system of ECM elements. In this way we can model a finite heat source without the infinite-source assumption, which would have overpredicted temperatures and rock dryout. Because of the approximate symmetry plane at the fracture midplane, we modeled the half-domain lying on one side of the fracture. Heat transfer across the air gap from the heater to the borehole wall is modeled using the $\Delta T^{4}$ radiation law. Grid resolution in the fracture plane was on the order of $0.1 \mathrm{~m}$ within the zone of interest in the vicinity of the heater. Grid sizes in the matrix next to the fracture were on the order of hundreds of micrometers. The resulting model has approximately 19,000 elements and takes around 10-20 hours to run on the IBM RISC 6000/550. A pure-ECM model was also run for comparison.

Cases were run for fracture apertures of 100,524 , and $1048 \mu \mathrm{m}$, corresponding to $k_{\mathrm{b}}=$ $0.280,40$, and 320 darcies, respectively, consistent with the range of gas permeability measurements at G-tunnel and Yucca Mountain. Fracture characteristic curves were those for a sandy material. Matrix porosity (20\%), intrinsic matrix permeability (1.9 microdarcies), and initial liquid saturation $(60 \%)$ were based on laboratory measurements. The capillary parameter $\alpha$ in the van Genuchten matric potential correlation was calibrated using an imbibition test [8]; the value of the $m$ parameter was taken from Peters et al. [9]. The calibrated a effectively reduces the matric suction by a factor of 40 with respect to the value in Peters et al. [9].

Temperature histories at the lower borehole wall and at points $0.55 \mathrm{~m}$ below and $2.4 \mathrm{~m}$ above the heater axis showed good agreement (Fig. 1). The 1048- $\mu \mathrm{m}$ case shows a higherthan-measured temperature above the heater, possibly because buoyant gas-phase convection is being overpredicted. The 280 and $524-\mu \mathrm{m}$ cases appear to give the best fit. The three cases give a good idea of the sensitivity of temperature on aperture, which in the field is highly spatially variable. The good agreement of temperature at the borehole was somewhat surprising, considering that there was a $30-40^{\circ} \mathrm{C}$ difference between the top and bottom of the heater container surface, a difference that was also observed in a laboratory benchtop experiment. Previous calculations using a linear heat transfer model across the air gap gave slightly higher temperatures [10] than measured. Rock matrix dryout volume, as 
measured by the neutron probes, was predicted reasonably well by both DFM and ECM (Fig. 2). The narrower dryout predicted by the DFM is caused by calculated flow resistance to vapor as it escapes from the matrix into the fractures; the ECM approach, because of its equilibrium assumption, has no matrix-to-fracture resistance. However, closer agreement by the ECM indicates that boiling is not being "throttled" by the matrix, perhaps because of microfractures not considered in our model or because the effective fracture spacing in the field was smaller. In the 524- and $1048-\mu \mathrm{m}$ cases, the ECM predicts much more buildup of condensate in the matrix, whereas the DFM predicts much less because of higher condensate drainage fluxes and upward vapor dispersal by buoyant convection. Some condensate buildup is predicted by both approaches in the $100-\mu \mathrm{m}$ case. Note that the diameter of the averaging kernel "seen" by the neutron probe was approximately $30 \mathrm{~cm}$ [8]. Consistent with field measurements, the 1048- $\mu \mathrm{m}$ DFM predicts slightly more drying below and slightly less drying above the heater.

The $100-\mu \mathrm{m}$ DFM predicts very little nonequilibrium condensate drainage in the fracture plane, as indicated by the liquid saturation in the fracture plane, while there is significant condensate drainage in the $1048-\mu \mathrm{m}$ case (Fig 3). At early times fracture flow in the $1048-\mu \mathrm{m}$ case is dominated by gravity (Fig. $3 \mathrm{c}$ ); at the end of the full-power heating period (Fig. 3d), buoyant gas-phase convection begins to play an important role by moving vapor from below to above the heater, where it condenses. Figures $4 \mathrm{a}, \mathrm{c}$ show the dimensionless saturation in the matrix, averaged in the direction transverse to the fracture plane. The shapes of the contours reflect the shape of condensate in the fracture. (The dimensionless saturation is the normalized amount of dryout compared to initial saturation. It equals one at full saturation and minus one at complete dryout.) Figures $4 \mathrm{~b}, \mathrm{~d}$ show the dimensionless matrix saturation in the vertical plane in the heater centerline perpendicular to the fracture plane. The vertically symmetric profile in the $100-\mu \mathrm{m}$ case indicates that the effect of gravity in the fracture is negligible, while in the $1048-\mu \mathrm{m}$ case, the matrix below the heater is drier while that above is wetter (as observed in the field test), because of buoyant convection. Our model results indicate that buoyant convection probably played a role in vapor movement. In both cases drying occurs preferentially next to the borehole and fractures, which was also observed in the test.

\section{MODELING DRIFT-SCALE BEHAVIOR IN THE REPOSITORY}

A DFM was developed for a drift-scale calculation simulating possible conditions at the potential repository site at Yucca Mountain. A single symmetry cell from an infinite array of drifts was modeled with discrete fracture planes spaced $0.33 \mathrm{~m}$ apart transverse to the drift axis. Fractures of various apertures were modeled. Areal mass loadings were 40, 48, and 60 MTU/acre (MTU = metric tons of uranium equivalent), corresponding to center-to-center drift spacings of 120,100 , and $80 \mathrm{~m}$, respectively. The WP centers are spaced $6 \mathrm{~m}$ apart in the drift and an oldest-fuel-first receipt scenario with 26-yr-old spent nuclear fuel, and a mix of 40 BWR and 21 PWR WPs were assumed for the decay-heat-generation curve [11]. The 40 MTU/acre case is characterized by cylindrical boiling zones that never coalesce between drifts, the boiling zones in the $48 \mathrm{MTU} /$ acre case barely coalesce, and the boiling zones in the $60 \mathrm{MTU} /$ acre case coalesce into a single tabular boiling zone centered at the repository horizon. The effect of repository ventilation on the moisture and heat transport was not considered. The model extends from the ground surface to the water table. Various units described by Peters et al. [9] were treated as horizontal layers of constant thickness, as was done by Buscheck et al. [11], along with uniform fracture aperture over all units.

Figure 5 shows the vertical profile of bulk liquid saturation intersecting the WP axis. An interesting result is that the bulk saturations predicted by the ECM and DFMs eventually agree in a few hundred years. During approximately the first $100 \mathrm{yr}$ after emplacement, the DFM predicts significant nonequilibrium drainage of condensate from above to below the repository through the fracture, as indicated by the vertically asymmetric bulk saturations 
profile in Fig. 6, while the ECM predicts very little drainage during this period. After less than $100 \mathrm{yr}$, the nonequilibrium condensate shedding behavior (as characterized by drainage around and below the boiling zones) ceases in the DFM, and the system approaches the same state as predicted by the ECM; both the ECM and DFM predict condensate refluxing in fractures above the repository for thousands of years after boiling fronts between drifts coalesce. The close agreement of the ECM with the DFM despite the presence of fracture flow is the result of the matrix becoming saturated in the condensation zone. Our model assumed homogeneous connectivity in the fracture, but long-term refluxing can occur without boiling zone coalescence if horizontal fracture connectivity above the boiling zone is poor. The characteristic time for the eventual quasi-equilibrium between the fractures and matrix will be longer if a larger fracture spacing was used; this effect will be investigated in future work.

The tendency for downward drainage of condensate flow in fractures to decrease with time is related to the decrease in specific thermal flux (i.e., thermal flux per unit area of outer boiling boundary) at the boiling zone. The causes of the decrease are (1) decrease in WP heat output and (2) increase in the area of the boiling boundary as the boiling front expands. The local condensate flux, which is approximately proportional to the thermal flux, eventually becomes so small that the matrix imbibes most or all of the condensate. The point at which this transition occurs can be expressed in terms of the critical flux for fracture-dominated flow [12]. Heterogeneity of fracture and matrix properties may delay the transition by increasing local condensate flux through flow focusing. A higher initial matrix saturation than that assumed here will decrease imbibition fluxes and prolong condensate drainage.

\section{CONCLUSIONS}

Calculations of the G-tunnel heater test show that gravity drainage and buoyant gasphase convection are likely reasons why condensate buildup in the matrix was not observed in the in situ heater test. Preferential drying below and wetting above the heater lends some support for the possibility that buoyant convection in the fractures is a factor driving moisture movement. Temperature prediction by all models were good, reflecting the fact that heat transfer in the rock was primarily by thermal conduction. Because of the short duration and small spatial scale of the test, the local condensate drainage flux during the Gtunnel test was probably much higher than that to be expected for a repository beyond the first few hundred years.

DFM drift-scale repository simulations suggest that nonequilibrium condensate shedding ceases less than 100 yr after waste emplacement. The ECM agrees with the DFM after this early period. Refluxing of condensate in fractures above the repository predicted by ECM agrees with that predicted by DFM. In future work we will determine the sensitivity of our simulation results to fracture spacing and heterogeneous matrix and fracture distributions and extend the calculations to larger repository scales.

\section{ACKNOWLEDGEMENTS}

We acknowledge the review of Ken Jackson, the editorial assistance of Peter Murphy, and the graphical support of Rick Wooten. This work was supported by the Yucca Mountain Site Characterization Project and performed under the auspices of the U.S. Department of Energy by Lawrence Livermore National Laboratory under Contract W-7405-Eng-48.

\section{REFERENCES}

1. T. A. Buscheck and J. J. Nitao, "The Importance of Thermal Loading Conditions to Waste Package Performance at Yucca Mountain," in Scientific Basis for Nuclear Waste 
Management XVIII, T. Murakami and R.C. Ewing, Eds. (Materials Research Society, Pittsburg, PA, 1994).

2. T. A. Buscheck and J. J. Nitao, "The Impact of Repository Heat on Hydrological Behavior at Yucca Mountain," Proc. of the Fifth Annual Inter. Conf. High Level Radioactive Waste Management (American Nuclear Society, LaGrange Park, IL, 1994).

3. J. J. Nitao, "Numerical Modeling of the Thermal and Hydrological Environment around a Nuclear Waste Package using the Equivalent Continuum Approximation: Horizontal Emplacement," Lawrence Livermore National Laboratory, Livermore, CA, UCID-21444 (1988).

4. K. Pruess, J. S. Y. Wang, and Y. W. Tsang, "On Thermohydrologic Conditions near HighLevel Nuclear Wastes Emplaced in Partially Saturated Fractured Tuff," Water Resour. Res. 26 (6), 1235-1248 and 1248-1261 (1990).

5. P. A. Forsythe, "Radioactive Waste Disposal Heating Effects in Unsaturated Fractured Rock," Numerical Heat Transfer Part A-Applications 17 (1), 29-51 (1990).

6. J. J. Nitao, "The NUFT Code for Modeling Nonisothermal, Multiphase, Multicomponent Flow and Transport in Porous Media," EOS Supplement 74 (3), 313 (1993).

7. A. L. Ramirez (ed.), "Prototype Engineered Barrier System Field Test (PEBSFT) Final Report," Lawrence Livermore National Laboratory, Livermore, CA, UCRL-ID-106159 (1991).

8. T. A. Buscheck and J. J. Nitao, "Estimates of the Width of the Wetting Zone Along a Fracture Subjected to an Episodic Infiltration Event in Variably Saturated, Densely Welded Tuff," Lawrence Livermore National Laboratory, Livermore, CA, UCID-21579 (1988).

9. R. R. Peters, E. A. Klavetter, I. J. Hall, S. C. Blair, P. R. Hellers, and G. W. Gee, "Fracture and Matrix Hydrologic Characteristics of Tuffaceous Materials from Yucca Mountain, Nye County, Nevada," Sandia National Laboratories, Albuquerque, NM, SAND84-1471 (1984).

10. T. A. Buscheck and J. J. Nitao, "Modeling Hydrothermal Flow in Variably Saturated, Fractured, Welded Tuff During the Prototype Engineered Barrier System Field Test of the Yucca Mountain Project," Lawrence Livermore National Laboratory, Livermore, CA, UCRL-JC-106521, 1991.

11. T.A. Buscheck, J.J. Nitao, and L.D. Ramspott, "Localized Dryout: An Approach for Managing the Thermal-Hydrological Effects of Decay Heat at Yucca Mountain," Proceedings Materials Research Society XIX International Symposium on the Scientific Basis for Nuclear Waste Management, Materials Research Society, Pittsburgh, PA, 1995.

12. J. J. Nitao, T. A. Buscheck, and D. A. Chesnut, "Implications of Episodic Nonequilibrium Fracture-Matrix Flow on Repository Performance," Nucl. Tech. 104 (3), 385-401 (1993). 


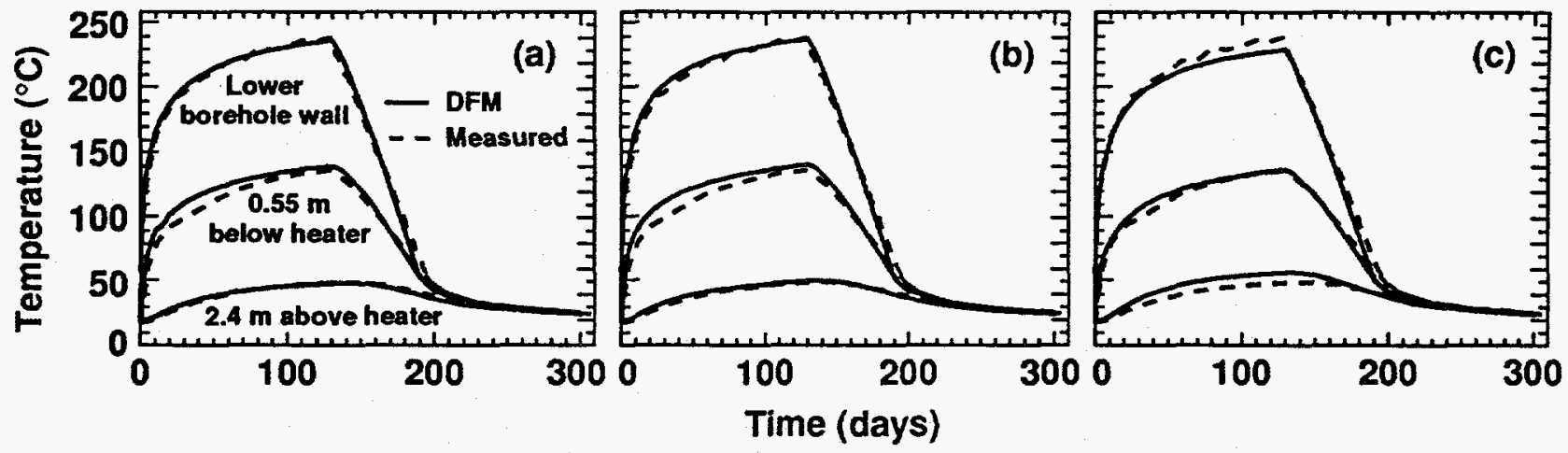

Figure 1. Temperature histories at three points on the heater midplane for fracture apertures of (a) $100 \mu \mathrm{m}$, (b) $524 \mu \mathrm{m}$, and (c) $1048 \mu \mathrm{m}$. 


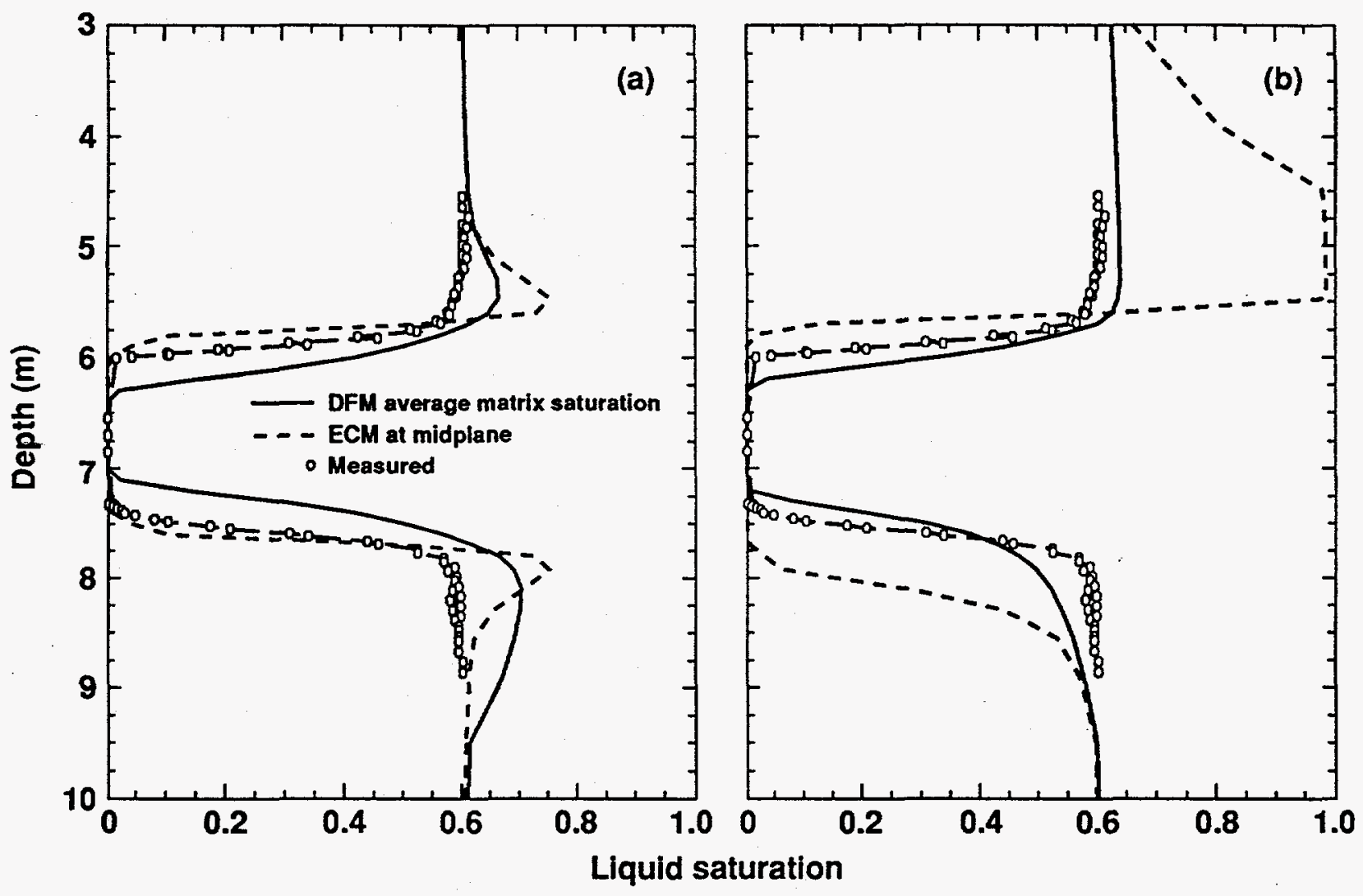

Figure 2. Vertical profile of ECM bulk liquid saturation and DFM matrix-averaged liquid saturation in heater midplane at 130 days for fracture apertures of (a) $100 \mu \mathrm{m}$ and (b) $1048 \mu \mathrm{m}$. 

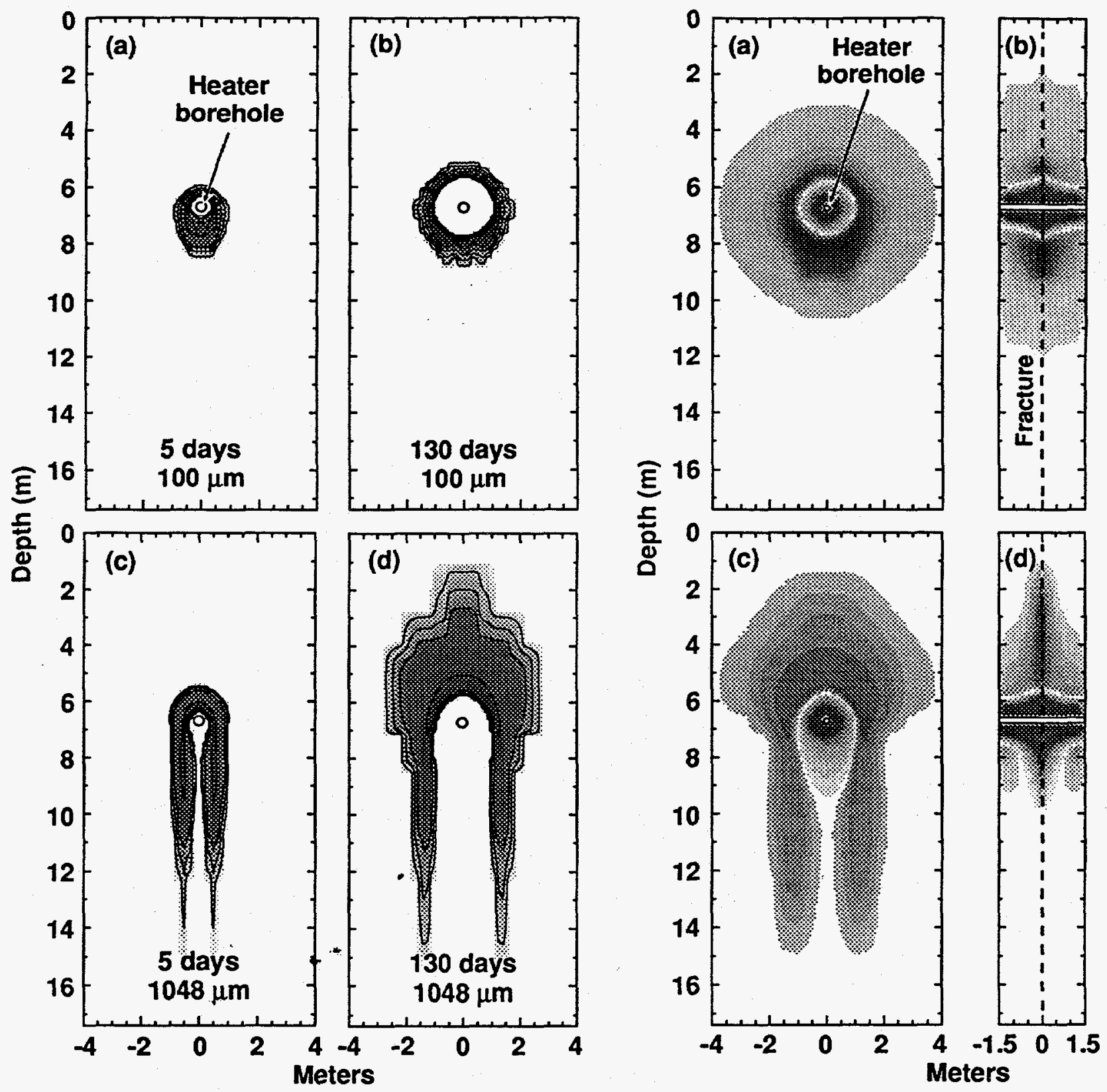

Figure 3. DFM calculated liquid saturation in fracture at (a) 5 days and (b) 130 days for $100 \mu \mathrm{m}$ fracture aperture, and (c) 5 days and (d) 130 days for $1048 \mu \mathrm{m}$ fracture aperture.
Figure 4. At 130 days we have the (a) DFM matrix-averaged dimensionless liquid saturation in heater midplane, (b) DFM matrix dimensionless liquid saturation in vertical plane along the heater axis, ECM bulk dimensionless liquid saturation in (c) heater midplane, and in (d) vertical plane along the heater axis. The medium-to-dark shading around the heater is the region of relative dryout, with dark shading indicating strong dryout. The narrow white shading around this region is no net change in saturation separating the regions of dryout and increased relative saturation. Dark shading in the latter region indicates large increases in saturation, while light shading indicates small increases. 


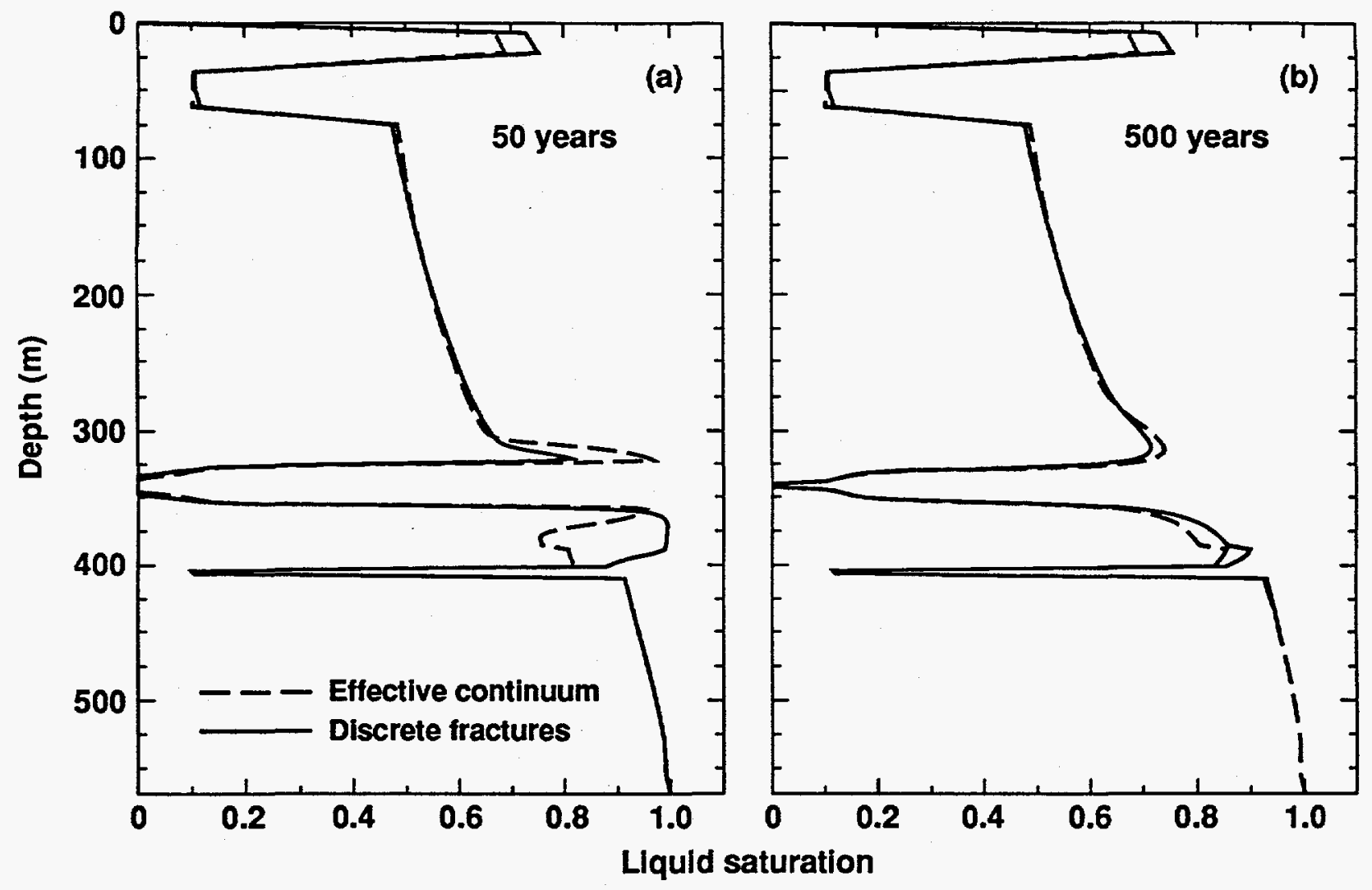

Figure 5. Vertical profile of ECM bulk liquid saturation and DFM matrix-averaged liquid saturation in transverse plane to drift (a) at 50 years and (b) 500 years from emplacement for drift-scale repository model using $k_{\mathrm{b}}=280$ millidarcy (corresponding to $100 \mu \mathrm{m}$ fractures) and areal mass loading of $48 \mathrm{MTU} / \mathrm{acre}$. 


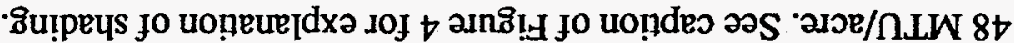

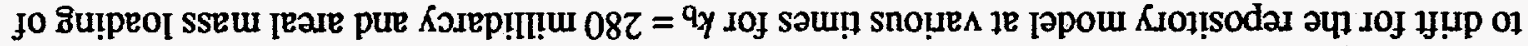

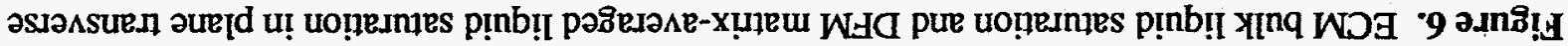

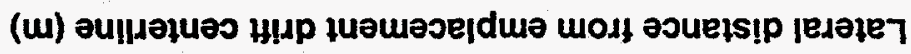

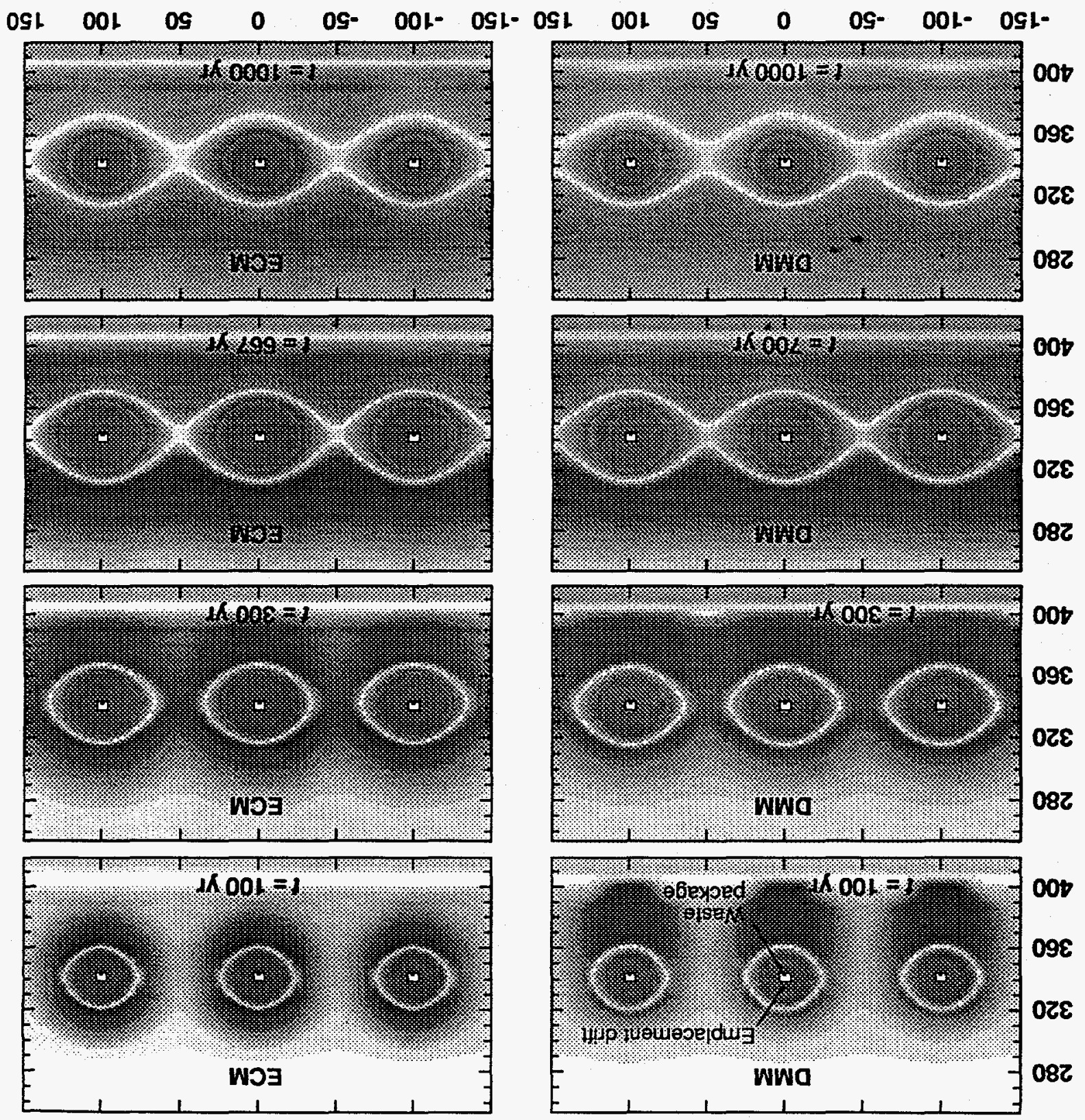

